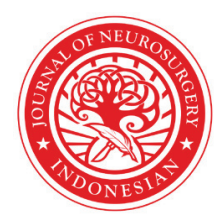

\title{
Disseminated metastatic craniopharyngioma: A malignant transformation
}

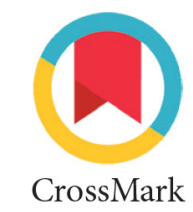

CrossMark

\author{
Morgan Eghosa', El Meldi Hakkou'², Charles Poluyi ${ }^{3 *}$
}

\section{ABSTRACT}

Introduction: Craniopharyngiomas are benign epithelial intracranial tumour with local aggressive and infiltrative propensity to adjacent structures. Though clinical manifestations are non-specific, but it classically present with features of endocrine dysfunctions, intracranial hypertension and visual deterioration. Malignant transformation of once recognized benign tumour is rare with only few cases reported in literature. However, no case of multiple disseminated malignant transformations has been reported before.

Case presentation: A 17-year-old boy whose initial diagnosis of adamantinimatous craniopharygioma (benign) was made at age two (2) after which he had both cerebrospinal fluid diversion with shunt and stereotactic guided cyst aspiration was presented. After a 15 year of regular follow-up, he presented once with recurrence (huge compressive cystic mass) and was re-operated with histology still remaining benign adamantinomatous craniopharyngioma and had stereotactic radiosurgery for the peripheral lesions. However, he came again 8 week later with altered level of consciousness and repeated imaging done revealed multiple metastatic disseminated supratentorial and infratentorial tumours which was confirmed to be malignant transformation of craniopharyngioma which is unlikely to be treatment-induced (radiosurgery) due to latent period of 8 week between radiosurgery and confirmation of malignancy.

Conclusion: Craniopharyngioma, a tumour once thought of as benign tumour only with no malignant potential even after treatment is curiously been accepted gradually to have malignant potential. It is important for all those actively involved in the management of craniopharyngioma to be aware that during course of management that the potential for malignant transformation do exist and exact cause still remain unclear.
'Irrua Specialist Hospital, Edo

State, Nigeria

${ }^{2}$ Hospital des Specialites, Rabat,

Morocco

${ }^{3}$ Lagos University Teaching

Hospital, Idi-Araba, Lagos, Nigeria

*Corresponding author: Poluyi Charles; Lagos University Teaching Hospital, Idi-Araba, Lagos, Nigeria; eddiepolz@yahoo.com
Received: 2019-05-09

Accepted: 2019-05-27 Published: 2020-04-08

Keywords: malignant transformation, metastatic craniopharyngioma, treatment management, tumour

Cite This Article: Egosa, M., Hakkou, E.M., Poluyi, C. 2020. Disseminated metastatic craniopharyngioma: A malignant transformation. Indonesian Journal of Neurosurgery 3(1): 12-15. D0I: 10.15562/ijn.v3i1.63

\section{INTRODUCTION}

Craniopharyngioma is a rare and slow-growing non-glial benign epithelial tumor located mainly in the infundohypophyseal axis (suprasellar and sellar region), which is known to arise from epithelial rest cell of involuted Rathke's pouch. ${ }^{1,2}$ It accounts for about $3 \%$ of intracranial tumors and $5-10 \%$ of pediatric brain tumors, and is more common in the pediatric age-group, though it has a bimodal age distribution between the first and fifth or sixth decade. ${ }^{1,2}$

Despite being a benign tumor, craniopharyngioma has been known to be locally invasive and aggressive, with great potential for recurrence, especially after incomplete surgical resection. However, despite being locally aggressive and recurrent after incomplete surgical resection, the cytological and histopathological findings remain benign. ${ }^{3}$ This brings about the curiosity in the findings in some literature from the United Kingdom and Japan of the presence of malignant transformation or malignant changes in craniopharyngioma. ${ }^{4-6}$

We report a case of craniopharyngioma with multiple disseminated supratentorial and infratentorial malignant transformation 15 years after initial diagnosis as a benign adamantinomatous type.

\section{CASE PRESENTATION}

We present a case of a 17-year-old male diagnosed at two years of age with craniopharyngioma with initial presentation of epilepsy (grand mal seizure type) and features of intracranial hypertension from hydrocephalus with magnetic resonance imaging (MRI). MRI findings are suggestive of craniopharyngioma (entirely cystic) (Figure 1). He had ventriculoperitoneal shunt (VPS) and subsequently aspiration of a cyst under stereotactic guidance.

Fifteen years after initial diagnosis, treatment and follow-up, he presented with a deteriorating 


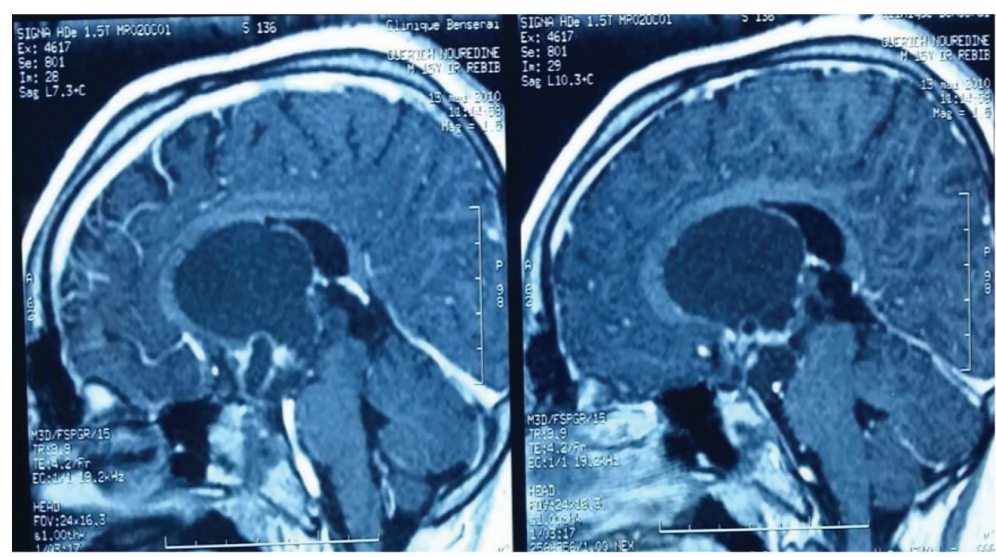

Figure 1. MRI on presentation, suggestive of craniopharyngioma
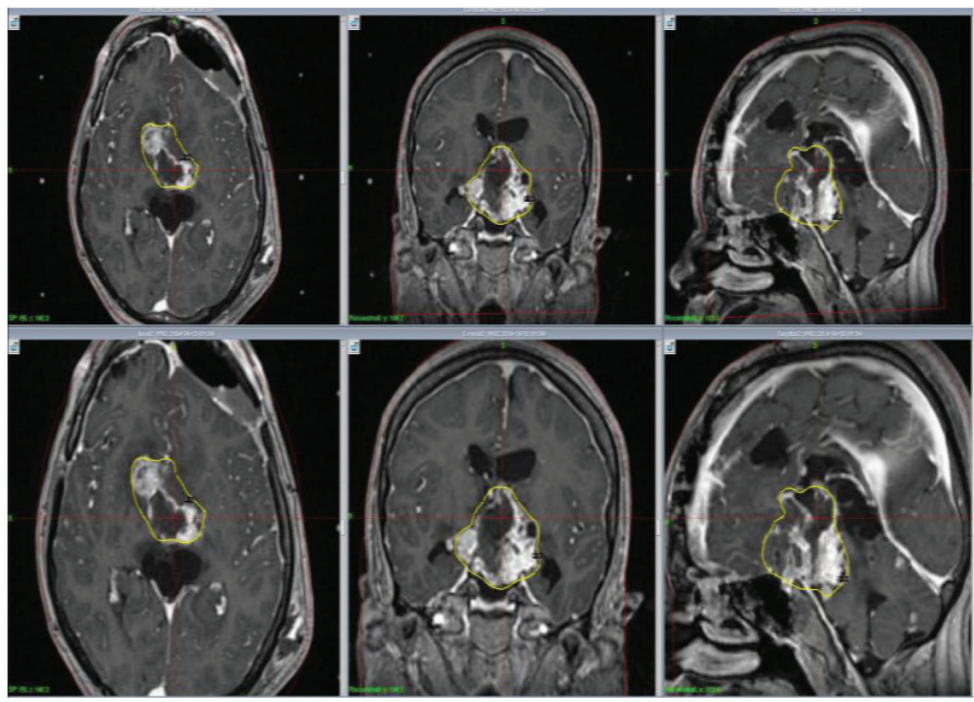

Figure 2. Post-operative, tumordebulking via interhemispheric transcallosal approach
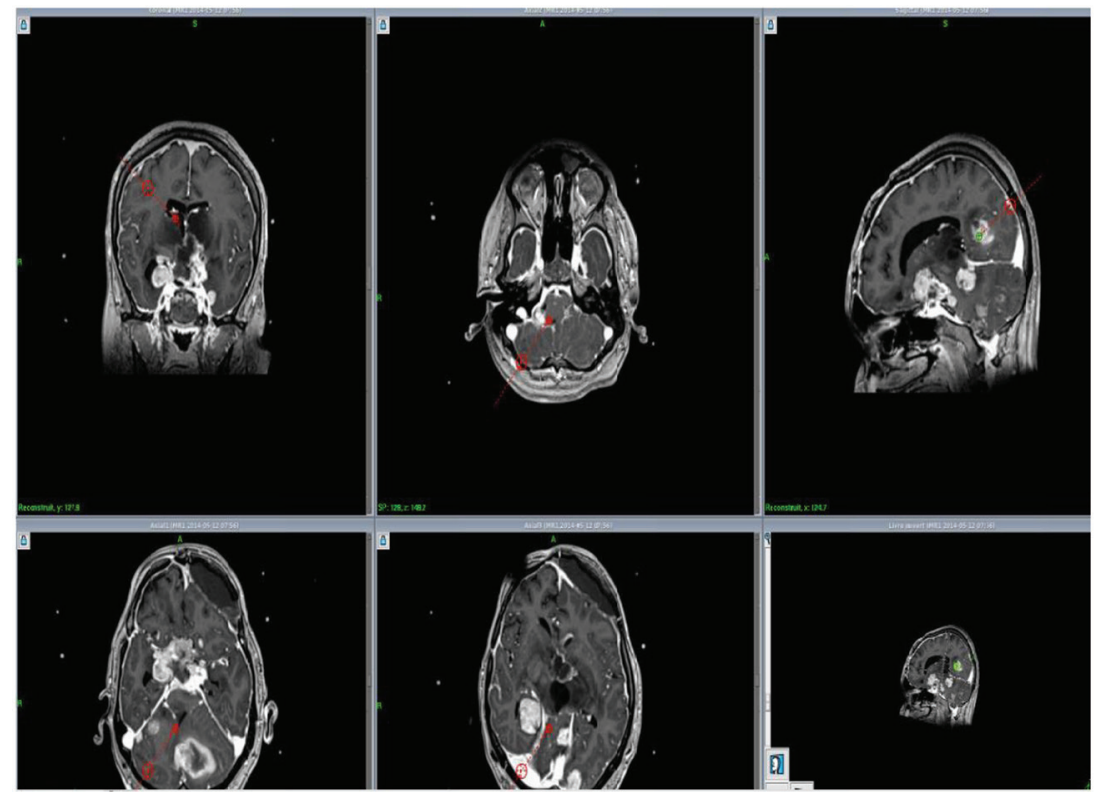

Figure 3. Tumors seen in the supratentorial and infratentorial region level of consciousness with compressive enlargement of the recurrent cyst as seen on the MRI. He had stereotactic guided cyst aspiration with improvement in symptoms observed. He subsequently had tumor debulking via interhemispheric transcallosal approach (Figure 2). The residual tumor was treated using Gamma Knife radiosurgery at $9 \mathrm{~Gy}$ for the peripheral residue.

After eight weeks, the patient seemed to experience deteriorating level of consciousness after an initial improvement, which necessitated admission into the intensive care unit. Radiological images revealed multiple tumor dissemination (outside the primary site and path of initial surgical intervention) tumors seen in the supratentorial and infratentorial region (Figure 3).

A biopsy was done under stereotactic guidance with histopathological examination revealing evidence of a malignant transformation of craniopharyngioma. The patient's clinical condition deteriorated and died a few days after the diagnosis of malignant transformation of craniopharyngioma.

\section{DISCUSSION}

Craniopharyngioma is a common non-glial intracranial tumor, though a rare central nervous system (CNS) tumor of benign histopathology enlisted as grade 1 tumour according to the fourth edition of the World Health Organization (WHO) classification of tumours of the central nervous system, published in 2007. ${ }^{1}$ Clinical features are non-specific and are dependent on age and size of the mass. Most cases of craniopharyngioma present with three major clinical manifestations, including progressive visual deterioration from direct compressive effect of the mass or indirect from raised intracranial pressure/papilloedema, intracranial pressure from both mass effect and hydrocephalus, and endocrine dysfunctions caused by pituitary-hypothalamic axis compression. ${ }^{3,7-9}$

The patient reported above presented with an unusual presentation of epilepsy, which is uncommon at two years of age, with endocrine disturbances as the common manifestation from this age-group. Craniopharyngioma is still believed to arise from the remnant of Rathke's pouch and is occasionally referred to as a nonneoplastic malformation with a linear growth curve potential. Two types of craniopharyngioma have been recognized, namely the adamantinomatous and papillary type, which are mainly seen in the young and adult group aged five to 14 years and the fifth decade of life, respectively. ${ }^{1,2,10}$ The adamantinomatous type is characterized by cyst, calcification, and cholesterol deposit often described as 'motor oil'. These features are often 
lacking in the papillary type, except for it being described to be made up of well-differentiated squamous epithelial with anastomotic fibrovascular stroma. The adamantinomatous variant has an illdefined, less circumscribed pattern and often shows infiltrative or invasive growth pattern, unlike the well-circumscribed papillary, which is less adherent to local structures and may be more amenable to complete surgical resection with a potentially more favourable outcome. This is still a subject for discussion by many authors. ${ }^{11,12}$

The main challenge following the treatment of this pathology is recurrence. ${ }^{11}$ Following gross total resection (GTR), the recurrence rate is about $20 \%$, and $60 \%$ with incomplete resection. Repeated operations following recurrence are more difficult with attendant high morbidity and mortality. ${ }^{3,11}$ In this case report, the clinical features of recurrence were observed after 15 years of VPS with stereotactic cyst aspiration.

Radiosurgery is a veritable alternative with proven efficacy in patients with incomplete surgical resection resulting in a reduction in tumour recurrence to about $30 \%{ }^{3,11}$ Generally, the 5-year survival rate is about $80 \%$ following treatment for this lesion. ${ }^{13}$ The case under-report above had $9 \mathrm{~Gy}$ radiotherapy following recurrence with clinical improvement noticed.

Malignant transformation of craniopharyngioma is a rare entity in the literature, with only 24 cases reported so far in the literature. However, none of them reported cases of disseminated multiple malignant transformations in the supratentorial and infratentorial region, which we reported. The first reported case was in 1986. Several malignant histological cases have been noted, amongst them is the squamous cell carcinoma within sites of previous resections or remote away from the site of previous surgery. ${ }^{4-6,11,14}$ Little is known about the cause and natural history of malignant transformation of craniopharyngiomas. ${ }^{4-6}$

In our case report, it was observed that after intervention for recurrence, histology still remained benign, but a latent period of eight weeks was observed between intervention and confirmation of disseminated malignant transformation. A 48-yearold patient who developed malignant change after 35 years of initial diagnosis of craniopharyngioma was reported by Nelson et al. ${ }^{4}$ This patient died from complications of upper gastrointestinal bleeding and respiratory tract infection. Kristopaitis et al. reported a 42-year-old woman diagnosed of malignant transformation (squamous cell carcinoma involving the nasal cavity, sphenoid and ethmoidal sinuses remote from the site of previous surgery) after 15 years of initial diagnosis of benign craniopharyngioma with radiation-related therapy been linked as a possible cause. ${ }^{15}$

The exact mechanism responsible for malignant transformation in benign craniopharyngiomas is still unknown. Nelson et al. hypothesized a causal relationship between radiation therapy and malignant transformations of craniopharyngiomas. ${ }^{4}$ The occurrence of malignant tumour after radiosurgery has been documented in the literature. ${ }^{16-17}$ Radiation therapy has been implicated in the development of secondary neoplasms in 5 cases. $^{18}$

Radiosurgery for benign brain tumours in adults has been noted with numerous side effects; Al-Mefty et al. reported that the latency for secondary neoplasms after radiation treatment ranges from 4 years to 30 years, with a median of 12.5 years. ${ }^{19}$ The case reported by Kristopaitis et al. suggested a causal relationship between radiation therapy and the development of malignant craniopharyngioma. ${ }^{15}$ However, the majority of patients who had radiosurgery, which was used to prevent recurrence of craniopharyngioma, did not result in malignant transformation to a squamous cell carcinoma. Therefore, radiation-induced malignant transformation is a distinctly rare event.

However, in our case report, the time difference between radiotherapy and time of diagnosis of malignant transformation was eight weeks compared to a minimum of 48 months as reported by Al-Mefty et al. ${ }^{19}$ and it is very unlikely the malignant transformation is caused by gamma knife radiosurgery in this case report based on this short time interval between radiotherapy and malignant craniopharyngioma.

Although malignant transformation in craniopharyngiomas is uncommon, neurosurgeons and pathologists should be aware of this rare occurrence. Local invasion, particularly in adamantinomatous craniopharyngiomas, is a characteristic and not a sign of malignant events. However, dysplastic features in craniopharyngiomas, particularly in patients who underwent radiotherapy, should be critically examined and follow-up closely. ${ }^{2}$

\section{CONCLUSION}

We have presented a case of malignant transformation of craniopharyngioma, which has not been reported as disseminated previously in the literature. Craniopharyngioma, a tumor that was once thought of as benignonly with no malignant potential even after treatment, is curiously been accepted gradually to have malignant potential.

It is important for those who are actively involved in the management of craniopharyngioma 
to be aware that during management, the potential for malignant transformation does exist but the exact cause remains unclear.

\section{CONFLICT OF INTEREST}

None of the authors of this paper has a financial or personal relationship with other people or organizations that could inappropriately influence or bias the content of the paper.

\section{FUNDING}

There is no funding available for this case report.

\section{AUTHORS' CONTRIBUTIONS}

All authors equally contributed immensely; Morgan $\mathrm{E}$ is the coordinator lead surgeon of the case.

\section{REFERENCES:}

1. Louis DN, Ohgaki H, Wiestler OD, Cavenee WK, Burger PC, Jouvet A, et al. The 2007 WHO classification of tumours of the central nervous system. Acta Neuropathol. 2007; 114(2): 547. DOI: 10.1007/s00401-007-0278-6.

2. Thapar K, Kovacs K. Neoplasms of the sellar region. In: Bigner DD, Mc-Lendon RE, Bruner J.(eds.) Russel and Rubinstein's Pathology of Tumours of the Nervous System. Oxford University Press; 1998. p. 561-580.

3. Samii M, Tatagiba M. Surgical management of craniopharyngiomas: A review. Neurol Med Chir (Tokyo). 1997; 37(2): 141 - 149. DOI: 10.2176/nmc.37.141.

4. Nelson GA, Bastian FO, Schlitt M, White RL. Malignant transformation in craniopharyngioma. Neurosurgery. 1988; 22(2): 427 - 429. DOI: 10.1227/00006123-19880200000029 .

5. Akachi K, Takahashi H, Ishijima B, Nakamura Y, Oda $\mathrm{M}$, Takizawa $\mathrm{T}$, et al. Malignant changes in a craniopharyngioma. No Shinkei Geka. 1987; 15(8): 843 848.

6. Suzuki F, Konuma I, Matsumoto M, Aoki M, Hayakawa I. Craniopharyngioma with malignant transformation--A report of two cases. Gan No Rinsho. 1989; 35(6): 723 - 728.

7. Perry A, Louis DN, Scheithauer BW, Budka H, et al. Meningiomas. In: Louis DN, Ohgaki H, Wiestler OD, Cavenee WK. (eds.) WHO Classification of Tumours of the Central Nervous System. Lyon: IARC Press; 2007. p. $164-$ 172.
8. Yaşargil MG, Curcic M, Kis M, Siegenthaler G, Teddy PJ, Roth P. Total removal of craniopharyngiomas. Approaches and long-term results in 144 patients. J Neurosurg. 1990; 73(1): 3 - 11. DOI: 10.3171/jns.1990.73.1.0003.

9. Müller HL. Consequences of craniopharyngioma surgery in children. J Clin Endocrinol Metab. 2011; 96(7): 1981 1991. DOI: 10.1210/jc.2011-0174.

10. Nielsen EH, Feldt-Rasmussen U, Poulsgaard L, Kristensen LO, Astrup J, Jorgensen JO, et al. Incidence of craniopharyngioma in Denmark $(\mathrm{N}=189)$ and estimated world incidence of craniopharyngioma in children and adults. J Neurooncol. 2011; 104(3): 755 - 763. DOI: 10.1007/ s11060-011-0540-6.

11. Weiner HL, Wisoff JH, Rosenberg ME, Kupersmith MJ, Cohen H, Zagzag D, et al. Craniopharyngiomas: A clinicopathological analysis of factors predictive of recurrence and functional outcome. Neurosurgery. 1994; 35(6): 1010 - 1. DOI: 10.1227/00006123-199412000-00001.

12. Eldevik OP, Blaivas M, Gabrielsen TO, Hald JK, Chandler WF. Craniopharyngioma: radiologic and histologic findings and recurrence. AJNR Am J Neuroradiol. 1996; 17(8): $1427-1439$.

13. Bunin GR, Surawicz TS, Witman PA, Preston-Martin S, Davis F, Bruner JM. The descriptive epidemiology of craniopharyngioma. J Neurosurg. 1998; 89(4): 547 - 51. DOI: $10.3171 /$ jns.1998.89.4.0547.

14. Sofela AA, Hettige S, Curran O, Bassi S. Malignant transformation of craniopharyngiomas. Neurosurgery. 2014; 75(3): 306 - 14. DOI: 10.1227/NEU.0000000000000380.

15. Kristopaitis T, Thomas C, Petruzzelli GJ, Lee JM. Malignant craniopharyngioma. Arch Pathol Lab Med. 2000; 124(9): 1356 - 60. DOI: 10.1043/0003-9985(2000)124<1356:MC>2.0.CO;2.

16. Kohn HI, Fry RJM. Radiation carcinogenesis. N Engl J Med. 1984; 310(8): 504 - 511. DOI: 10.1056/ nejm198402233100807.

17. Levitt SH. Secondary malignancies after radiotherapy. In: Dunst J, Sauer R. (eds) Late Sequelae in Oncology. Germany: Springer-Verlag; 1995. p. $279-289$.

18. Sogg RL, Donaldson SS, Yorke CH. Malignant astrocytoma following radiotherapy of a craniopharyngioma. Case report. J Neurosurg. 1978; 48(4): 622 - 7. DOI: 10.3171/ jns.1978.48.4.0622.

19. Al-Mefty O, Kersh JE, Routh A, Smith RR. The long-term side effects of radiation therapy for benign brain tumors in adults. J Neurosurg. 1990; 73(4): 502 - 12. DOI: 10.3171/ jns.1990.73.4.0502.

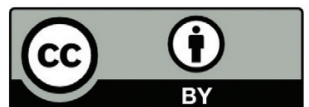

This work is licensed under a Creative Commons Attribution 